\title{
Unexplored Opportunities: Use of Climate- and Weather-Driven Early Warning Systems to Reduce the Burden of Infectious Diseases
}

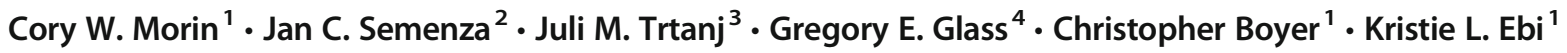

Published online: 22 October 2018

(C) Springer Nature Switzerland AG 2018

\begin{abstract}
Purpose of Review Weather and climate influence multiple aspects of infectious disease ecology. Creating and applying early warning systems based on temperature, precipitation, and other environmental data can identify where and when outbreaks of climate-sensitive infectious diseases could occur and can be used by decision makers to allocate resources. Whether an outbreak actually occurs depends heavily on other social, political, and institutional factors.

Recent Findings Improving the timing and confidence of seasonal climate forecasting, coupled with knowledge of exposureresponse relationships, can identify prior conditions conducive to disease outbreaks weeks to months in advance of outbreaks. This information could then be used by public health professionals to improve surveillance in the most likely areas for threats. Early warning systems are well established for drought and famine. And while weather- and climate-driven early warning systems for certain diseases, such as dengue fever and cholera, are employed in some regions, this area of research is underdeveloped.

Summary Early warning systems based on temperature, precipitation, and other environmental data provide an opportunity for early detection leading to early action and response to potential pathogen threats, thereby reducing the burden of disease when compared with passive health indicator-based surveillance systems.
\end{abstract}

Keywords Early warning systems $\cdot$ Climate $\cdot$ Infectious disease $\cdot$ Forecasting

\section{Introduction}

There are significant opportunities to protect and promote population health by moving from a health systems approach focused primarily on identification of causes and response to one of prediction and prevention, taking advantage of the significant environmental data describing the

This article is part of the Topical Collection on Global Environmental Health and Sustainability

Cory W. Morin

cwmorin@uw.edu

1 University of Washington, 4225 Roosevelt Way NE \# 100, Seattle, WA 98105, USA

2 European Centre for Disease Prevention and Control, Solna, Sweden

3 National Oceanic and Atmospheric Administration, Silver Spring, MD, USA

4 University of Florida, Gainesville, FL, USA status of our atmosphere and ecosystems that are associated with changing disease risk. This opportunity builds on robust research showing the numerous means through which weather, climate, and ecosystem status affect infectious disease ecology $[1,2]$. Research confirms that seasonality and the geographic distribution of many infectious diseases are associated with atmospheric conditions [3-6]. Consequently, these conditions can be used to forecast, weeks to months in advance, when and where outbreaks are likely to occur [7-9] (Table 1). Research also shows there can be complex interactions among weather and climate variables, and complex relationships with other factors affecting disease outbreaks (e.g., global travel and trade, population immunity) [10•] [11-13].

Effectively applying this knowledge requires methods for the robust use of environmental information in implementing intervention strategies and in policy formation. Critical elements to translate knowledge to application include monitoring environmental conditions at scales useful for implementation of interventions, conducting robust and timely surveillance, developing and deploying 
Table 1 Sample of published manuscripts about disease forecasting with information on the authors, the disease and location, and a brief summary of the study

\begin{tabular}{|c|c|c|}
\hline Author/year & Disease/location & Summary \\
\hline Hii et al. 2012 [7] & Dengue/Singapore & $\begin{array}{l}\text { Weather-based dengue forecasting model allowing } 16 \text {-week advanced warning of dengue } \\
\text { epidemic with high sensitivity and specificity. Used a time-series Poisson multivariate } \\
\text { regression model using weekly mean temperature and cumulative rainfall over the } \\
\text { period 2000-2010. }\end{array}$ \\
\hline Johansson et al. 2016 [8] & Dengue/Mexico & $\begin{array}{l}\text { Performance evaluation of seasonal autoregression models with and without climate variable } \\
\text { for forecasting dengue incidence in Mexico. Short-term and seasonal autocorrection were } \\
\text { key for improving short and long-term forecasting. Climate data did not significantly improve } \\
\text { the predictive power. Seasonal autoregressive models captured dengue variability, but better } \\
\text { models are needed to improve dengue forecasting. }\end{array}$ \\
\hline Semenza et al. 2016 [48] & $\begin{array}{l}\text { West Nile } \\
\text { virus/Europe }\end{array}$ & $\begin{array}{l}\text { Risk of West Nile virus (WNV) transmission in Europe projected using a multivariate model and } \\
\text { applied AB } 1 \text { climate scenario for } 2025 \text { and } 2050 \text {. Predicative prevalence of WNV infections in } \\
\text { the blood donor population also estimated. Projections reveal higher probability of WNV } \\
\text { infection at edges of transmission zones for 2025, and further expansion by } 2050 \text {, as well as } \\
\text { expanded prevalence in the blood donor population }\end{array}$ \\
\hline Davis et al. 2017 [49] & $\begin{array}{l}\text { West Nile virus/USA } \\
\text { (South Dakota) }\end{array}$ & $\begin{array}{l}\text { Use of a country-level logistic regression model to predict weekly probability of human } \\
\text { West Nile virus (WNV) cases as a function of temperature, precipitation, and index of } \\
\text { mosquito infection status. The model was applied in } 2016 \text { to make short-term (weekly) } \\
\text { and whole year (seasonal) forecasts. Model results were generally accurate, with an AUC } \\
\text { of } 0.856 \text { for short-term predictions. }\end{array}$ \\
\hline Shaman et al. 2017 [50] & Influenza/USA & $\begin{array}{l}\text { Humidity forcing was included in mathematical models describing influenza transmission and } \\
\text { retrospective forecasts for } 95 \text { cities across } 10 \text { seasons in the US were generated. Humidity } \\
\text { forcing improved forecast performance, and findings held for predictions of outbreak peak } \\
\text { intensity, peak timing, and incidence of } 2-4 \text {-week horizons. }\end{array}$ \\
\hline Pasetto et al. 2018 [51] & Cholera/Haiti & $\begin{array}{l}\text { A rainfall-driven, spatially-explicit meta-community model of cholera transmission was coupled } \\
\text { to a data assimilation scheme for computing short-term projections of the epidemic in near } \\
\text { real-time. The model was used to forecast cholera incidence for the months after the passage of } \\
\text { Hurricane Matthew (October-December 2016) and to predict the impact of a planned oral } \\
\text { cholera vaccination campaign. }\end{array}$ \\
\hline Merkord et al. 2017 [52] & Malaria/Ethiopia & $\begin{array}{l}\text { Disease surveillance and environmental monitoring (including precipitation and temperature } \\
\text { data) were integrated in support of operational malaria forecasting and interface with public } \\
\text { health in the Amhara region of Ethiopia using the EPIDEMIA computer system and EASTWeb } \\
\text { software programme. }\end{array}$ \\
\hline
\end{tabular}

early warning and forecasting tools, timely sharing of the information with public health professionals, and performing continuous evaluation of this interconnected system to maximize its efficiency and improve its efficacy.

Weather- and climate-driven forecasting and early warning systems are increasingly important in the context of climate and other environmental changes. Warming temperatures and changes in precipitation patterns can alter a pathogen's geographic range, seasonality, and intensity of transmission; therefore, the need to understand and predict new patterns of disease risk at various scales will become vital for better managing future health challenges [1]. Loss of biodiversity, from habitat fragmentation and other forms of environmental degradation, is also correlated with increased disease frequency [14]. Furthermore, the burden of emerging infectious diseases increased in recent decades, with risk associated with socioeconomic, environmental, and ecological factors [15]. Given these relationships and the rapid pace of global change, developing and improving early warning systems will be vital for preparing for and reducing the health impacts.

\section{Influence of Weather, Climate, and Other Environmental Variables on Disease Ecology}

Climate and other environmental variables impact multiple aspects of pathogen ecology. Heavy precipitation can increase the incidence of water- and food-borne diseases by washing contaminants and pathogens into water used for drinking and/ or agriculture, particularly in situations where waste treatment facilities are overwhelmed [6]. Temperature can accelerate pathogen development and/or replication in the environment. For example, the bacteria causing cholera, Vibrio cholerae, is associated with warmer sea surface temperatures [16]. Meteorological conditions can affect vectors and pathogens. Vector development, reproductive behaviors, and mortality rates are often impacted by ambient temperature, as is the extrinsic incubation period of some pathogens, such as the arboviruses [17]. Furthermore, aquatic habitats required for the immature stages of some vectors, like mosquitoes, depend 
on precipitation [17]. Rodent-borne pathogens, such as hantaviruses, are connected with climatic conditions through increased food availability from wetter conditions that permit larger rodent populations and increased contact between humans and rodents [18]. Air-borne pathogens are sometimes sensitive to humidity; patterns of specific humidity are consistent with differences in the seasonality of influenza outbreaks between tropical and temperate regions [19]. Soil-borne pathogens such as Coccidioides immitis, the soil fungus that causes valley fever, are influenced by soil moisture for growth and survival, and by wind for dispersion [20]. Similarly, meningitis is closely tied to wind, rainfall, and humidity, and those environmental parameters have been used to predict potential outbreaks in sub-Saharan Africa [21]. The strengths of these relationships vary in time and space, highlighting the importance of location-specific knowledge to inform decision making (example for Vibrio discussed below). The use of environmental information to inform early action by policy and decision makers is not unique to public health. The connection between climate and weather drivers, drought and famine, are well established and systems for predicting drought and famine are in place (e.g., Fews.net and Drought.org); this predictive capacity and experience can be harnessed to provide public health and related decision makers a significant opportunity to both optimize resources and reduce health burdens.

\section{Surveillance and Screening}

Passive surveillance systems are commonly used to detect diseases that pose significant risks to human health. Once detected, public health professionals and decision makers evaluate and respond to the risk of an outbreak and implement needed strategies to reduce epidemic potential. Unfortunately, passive surveillance systems do not identify a threat until the pathogen has reached a detectable threshold within the population. The time between exposure and clinical disease is often on the order of days, during which period the disease can spread widely. Subclinical infections and misdiagnosed cases make case detection even more challenging, and further delay appropriate responses. Health system authorities and health care personnel are informed about the cases through established communication channels. Policy recommendations then flow back through these channels, taking additional time. These delays can allow pathogen diffusion before effective interventions.

Screening is more sensitive to pathogen introduction but with added time and economic costs. By systematically testing for pathogens, it is possible to detect them regardless of clinical manifestation, as long as the tests are reliable and are used early and broadly enough in a potential outbreak. Active surveillance presumes that the targets of surveillance are known (so that emerging diseases are unlikely targets) and given the costs of maintaining such systems, prioritization of targeted pathogens need to be established. These, generally, are based on the cost tradeoffs of the system establishment and activity versus the costs of disease outbreaks and subsequent control efforts. Understanding and forecasting changing risks can facilitate more targeted active surveillance by identifying (1) the conditions required for transmission to occur (e.g., temperature thresholds) or (2) conditions that previously were associated with large epidemics.

\section{Moving from Surveillance and Response to Early Warning and Response Systems}

Early warning systems are atmospheric/environmental monitoring systems that can identify or predict conditions that are suitable for epidemics or disease emergence. Rapidly improving capacity to monitor and predict seasonal weather patterns allows for increased confidence in predicting climate and weather parameters that drive public health risks. Harnessing this investment and moving from surveillance and response to an early warning system as an approach to disease control can reduce suffering, save lives, increase the effectiveness of interventions, and efficiently use scarce public health resources. Early warning systems for climate-sensitive infectious diseases could reduce morbidity and mortality when combined with other important factors such as travel and herd immunity. These diseases are obvious targets because they are sensitive to environmental factors (e.g., weather events and seasonality) and importantly the methods for routine monitoring, often at fine spatial scales, have been established. Equally important, there are well-developed forecasting methods [22]. Figure 1 illustrates the advantages of early warning systems by comparing epidemic responses between the standard approach of passive surveillance and response (top) with integrating an early warning and response system (middle).

Building and using a climate-/weather-driven early warning system to reduce outbreaks of infectious diseases requires data, knowledge of ecological relationships in the disease system, tools, and actions as illustrated in Fig. 1 (bottom) and provided in an example using Vibrio (described later). Central to this system is a forecasting tool (often based on a model of disease processes) that evaluates the epidemic risk based on current and/or future atmospheric conditions [23]. The form of the tool will vary with regard to its model classification (e.g., empirical vs mechanistic) and data drivers (e.g., current observations vs forecasts). Lagged regression models are common forecasting tools because they correlate previously/currently observed conditions with later events and extrapolate when future outbreaks are likely, providing an opportunity for proactive actions before the first cases appear [24]. These models are relatively easy to build but require location-specific data and may be affected by spurious past correlations. Continued use and refinement of 

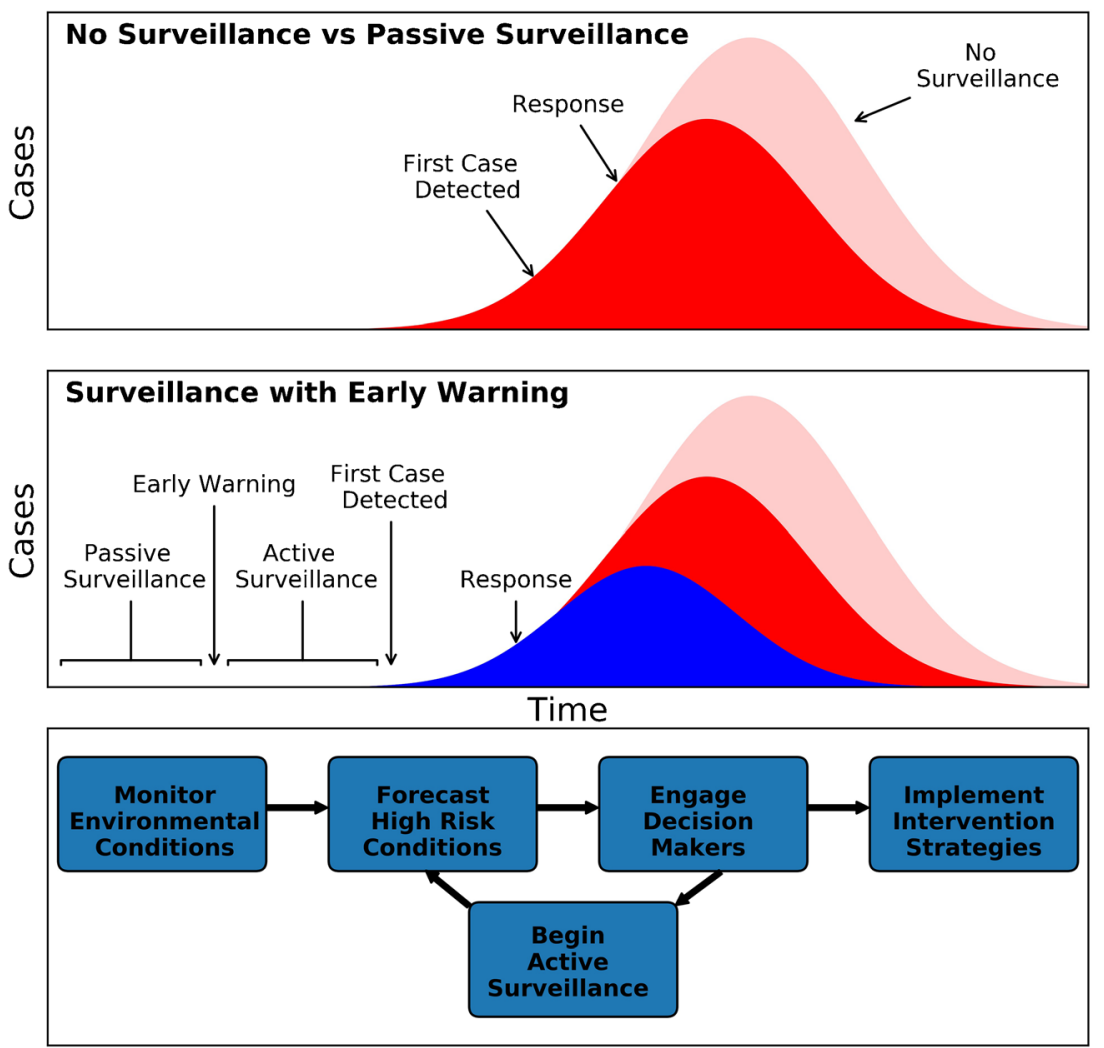

Fig. 1 Theoretical epidemic curves representing no surveillance (pink curve) vs passive surveillance (red curve) and response (top panel) and integrating an early warning system (blue curve, middle panel), showing the timeliness of surveillance, detection, and response. When only using passive surveillance (top panel), the first cases are detected only after enough transmission results in individuals showing symptoms, seeking medical attention, and getting tested for the pathogen, and whose doctor reports positive results. Additional time is then required to plan, organize, and initialize a response. In the middle panel, forecasts of high-risk conditions trigger an early warning alert that will initiate screening. Through screening or active surveillance, an infected individual can be detected much earlier and therefore the response also can be initialized earlier, reducing the magnitude of the outbreak. During the screening or active surveillance phase, it may also be possible to prepare for a response in the event that a case is detected and therefore reduce the time between detection and response. The steps and connections within an early warning system are shown on the bottom

months are often necessary to fully evaluate and prepare for potential epidemic threats. The scales of such data range from short-term weather predictions (1-10 days) to seasonal forecasts (1-6 months) to multi-decadal climate projections. The characteristics and skill of these forecast types are important when considering their use in an early warning system. Shortterm forecasts can be both specific and accurate within a 7-day lead time before the signal-to-noise ratio degrades. This may be an acceptable lead time for some systems, although it provides little time for preparation (e.g., training, awareness raising, initiation of preventative measures). Seasonal climate forecasts provide a longer lead time for planning and implementation; however, they are less certain and broader in scale compared to short-term forecasts. This is an area of active research with the potential to greatly enhance risk assessment (see North American Multi-Model Ensemble-NMME, http://www.cpc.ncep.noaa.gov/products/NMME/). Although important for long-term planning, climate change projections are not on a scale compatible with responding to epidemics. The appropriateness of any dataset for use in an early warning datasets, etc. Forecasts of conditions ranging from days to 
system is interdependent on the risk forecasting tool, the pathogen, and the goals of the public health professionals and decision makers. For example, because short-term forecasts tend to be more accurate than long-term forecasts, they can be very useful for heat early warning systems where preparation can be quick. Long-term forecasts, however, can facilitate the planning and strategic decision making required for health threats that require significant resources and/or fundamental changes in operations.

\section{Engaging Decision Makers with Risk Forecasts and Implementing Intervention Strategies}

Developing skillful forecasts is insufficient to prevent disease outbreaks; equally important are effective and timely interventions developed in collaboration with health system decision makers and personnel who will implement these interventions. Just knowing that weather conditions can lead to adverse health outcomes does not result in appropriate responses [26]. Key stakeholders should be involved in early warning system development to ensure the system fulfills their needs, is timely, and accounts for the specifics of implementing intervention strategies for the disease and region of interest. This involves understanding what information is needed and at what spatial scale for a useful forecast, specifying the criteria for activating (and deactivating) the implementation plan, deciding which measures will be implemented and when based on the forecast, the responsibilities of the partners, including with respect to communication and to whom information will be communicated, and how the system will be monitored and evaluated.

Forecasts of suitable conditions for a disease outbreak can trigger screening in places where and times when diseases are likely to emerge, and trigger preventive interventions such as disease control programs and vaccinations, where vaccines are available. Effective interventions, such as cleaning up mosquito breeding sites and public education, could reduce exposure to vectors and decrease the need for vaccination. Doing so would both improve the effectiveness of the response and could increase the effective use of scarce resources. This could be especially effective in areas on the margins of a pathogen's range where anomalies in climate can substantially alter risk. This combination of early information and targeted use of resources suggests that early warning systems are cost-effective approaches to manage the risks of emerging and re-emerging diseases. The World Health Organization has integrated this concept into its practice regarding Rift Valley Fever to facilitate earlier delivery of vaccine and personnel in high-risk areas thereby reducing the extent of the RVF outbreak [27].

Emerging infectious diseases (EID) are of public health concern due to the unanticipated nature of their emergence and impact [15]. Such events can strike unexpectedly and have dire consequences for society at large by causing human suffering, placing pressure on government resources, and inflicting economic damage. Risk forecasts are desirable to guide intervention strategies to accelerate the detection of EID and response capacity and possibly even prevent EID. Rather than detecting early cases of an outbreak, a more tactical strategy is to examine climatic and environmental conditions prior to an outbreak and then to intervene directly on the determinants of the infectious disease. Some of these determinants are more amenable to interventions than others. An example of engaging decision makers with risk forecasts and implementing intervention strategies involves the resurgence of domestic malaria transmission in Greece. Malaria was eliminated in Greece in 1974, but in 2009 a cluster of locally acquired Plasmodium vivax cases occurred among patients without a travel history to malaria-endemic regions. To guide malaria control efforts, areas suitable for malaria transmission in Greece were delineated [28]. The climatic and environmental suitability of transmission was mapped. These risk maps were delivered to the field investigation team and to the local decision makers, to help guide intervention strategies. Based on this risk forecast, other areas of Greece that were climatically and environmentally suitable for potential transmission were targeted for indoor residual spraying, aerial sprayings, provision of long-lasting insecticide-treated nets, active case detection, and mass drug administration. By engaging decision makers early in the process, subsequent malaria outbreaks in high-risk areas were prevented and transmission was interrupted in 2013 [29].

\section{Evaluation and Refinement of Early Warning Systems}

Integral to refining an early warning system is learning throughout the feedback loop between forecasting high-risk conditions, engaging decision makers, and beginning screening and active surveillance. Continual evaluation of the early warning system, through comparison of forecast results and subsequent case observations and actions taken, is necessary to determine its sensitivity and specificity, biases, utility, and any changes to these metrics [8]. This information improves each component of an early warning system. Skill scores at different lead times can determine how forecast accuracy changes to the point they are not helpful to decision makers.

A major challenge of evaluating forecasts is appropriately taking into account that successful interventions can suggest the forecast was inaccurate (e.g., although the forecast indicated where and when a disease outbreak was likely to occur, the outbreak did not happen because of the success of the interventions). This will make it difficult to differentiate a successful intervention from a false positive forecast. However, this is a general concern for any public health intervention when prevention rather than response to an ongoing crisis is the 
goal. One strategy is limited, upstream surveillance (such as pathogen surveillance in arthropod vectors) in high-risk zones as a monitoring tool that is performed as a crucial node in the decision tree before further intervention.

Screening provides additional data to integrate into the forecasting tool that can increase the robustness of lagged regression models by training them on a greater number of data points. This is especially important in locations with limited historical health data. For mechanistic models, it facilitates better parameterization and enables the model to adapt to an epidemic as it progresses. Consequently, the early warning system both dampens epidemics by accelerating response strategies and improves our ability to understand environmentally mediated risk by increasing data collection.

Implementing an early warning system does not increase the risk of missing epidemics in situations where passive surveillance continues. There is an economic cost to false positives, however, due to additional testing and other resource preparations. Calculations of skill scores will give a measure of the forecast utility by comparing its accuracy to the accuracy of a baseline forecast where epidemics are assumed to follow the long-term mean. This provides a "value-added" measure of the system.

\section{Challenges and Limitations of Early Warning Systems}

The use of weather- and climate-based early warning systems has the potential to fundamentally shift the paradigm from surveillance and response to planning, preparing for, and ultimately reducing health risks. Weather- and climate-based early warning systems have demonstrated value and the potential for much more use; however, disease forecasting and other models for early warning systems also have many limitations and challenges due in large part to both the complexity of the system and data availability. As discussed earlier, empirically based models require health data that may not be available. Even when health data are available, their resolution, collection methods, and timeliness may not be compatible with the modeling method. However, collaboration between forecasting and surveillance efforts can ensure synergy and resolve issues of incompatible data. Although data may be initially scarce, the system will grow more robust as data are collected over time and the forecasting system is refined.

A number of confounding factors can make it difficult to isolate the impact of weather and climate on infectious diseases. It is critical, therefore, to determine whether the goal is to develop a disease prediction model for early warning, or to develop an early warning system triggered by known environmental and social parameters, or both. The underlying drivers of emerging infectious diseases in Europe were identified, differentiated, and ranked according to their importance [13].
Such a ranking of the relative contribution of key drivers can help prioritize risk-based surveillance to forecast emergence and spread of infectious diseases [23, 30]. In Europe, travel and tourism, food and water quality, natural environment, global trade, and climate were the top five drivers of all identified EID $[13,31]$. In this analysis of drivers and determinants of EID, travel and tourism was the most distinct and also the most recurrent driver implicated in the emergence. Travel and tourism can be analyzed to forecast the risk of dengue importation. By modeling air passenger volume from dengue-active areas worldwide, the risk for importation can be predicted. An analysis of passenger volume into Europe found the risk of dengue importation to be greatest for Milan, Rome, and Barcelona in August, September, and October, precisely when the vector densities are the highest [32]. Thus, the model quantifies the likelihood and timing of importation which can be used to guide public health interventions. It informs public health policy for infectious disease control and prevention. With such risk forecasts, seasonal or sentinel surveillance can be enhanced and tailored to certain regions and time periods. A number of other drivers and determinants also were important contributors. For instance, evolving herd immunity can amplify or dampen an epidemic. Fortunately, it is possible to incorporate these other factors into forecasting systems. Studies exploring connections between weather, climate, and infectious disease often include socio-economic, demographic, and other variables into their analyses. A major challenge will be refining the relationships between environmental and human-mediated factors and infectious disease risk for individual locations.

Once built, operationalizing forecasting and early warning systems presents additional challenges. They require resources that are often limited. For example, these countries require disease surveillance and reporting systems, robust public health systems that can use and respond to the warnings, and expertise to continue developing and evaluating the system. The weather and climate challenges are to ensure the forecast tools and observations are spatially and temporally useful to public health professionals, and to sustain operational capacity for the forecasts, and the observational systems that support them. Furthermore, once a forecast system is developed, protocols need to be established to determine how and when to initiate active surveillance. This includes determining thresholds of risk, identifying who should be tested, and what are the important intervention strategies.

And even if the forecast system was completely accurate and timely, significant social, political, and institutional challenges to acting on the forecast information remain. Challenges of developing effective response strategies are illustrated by an example of the potential for early warning systems to prevent or reduce disease outbreaks. Investigation of an outbreak of hantavirus pulmonary syndrome in 19931994 in the Four Corners Region of the U.S. identified 
climatic, spatial, temporal, and environmental patterns, including increased precipitation associated with the 19911992 El Niño, likely increased disease risk. There is evidence that remotely sensed environmental data combined with El Niño-driven weather conditions could be used to forecast regions with higher levels of risk [18]. Extensive public education followed this outbreak. Media coverage about a possible increase in cases with the forecast of a strong El Niño in 19971998 led to the expectation that the number of reported cases would be limited because of increased awareness [33]. However, this El Niño resulted in a 5-fold increase in cases in regions that received increased rainfall in 1998.

\section{Example of an Operational Early Warning System for Emerging Infectious Diseases: the European Centre for Disease Prevention and Control Vibrio Map Viewer}

Vibrio spp. are aquatic bacteria, closely tied to environmental drivers, and which exemplify how weather, climate, and ecosystem status can affect infectious diseases ecology. They are marine bacteria that thrive in low-salinity water with elevated sea surface temperature (SST). Some of these bacteria are pathogenic to humans, including Vibrio cholera, $V$. parahaemolyticus, $V$. alginolyticus, and V. vulnificus [34-36]. Only V. cholera is associated with large epidemics; incidence of the others has increased over the years, in part due to the warming of the oceans [37-40].

The Baltic Sea has increasingly become an ideal habitat for these Vibrio species. As one of the largest brackish water bodies in the world, the Baltic Sea is warming at a disproportionate rate due to its northern latitude. Moreover, the Baltic Sea is projected to continue to warm, to decrease its salinity, to have decreased sea ice extent, and to experience further expansion of oxygen depleted "dead zones." These environmental changes are associated with recent outbreaks of Vibrio infections in the countries surrounding the Baltic Sea. Elevated SST during the summer months in 1994, 2003, 2006, 2010, and 2014 across much of the Baltic Sea was associated with reported Vibrio-associated illness [41-45].

By monitoring these environmental conditions in the Baltic Sea, an early warning system for public health can forecast the emergence of infectious diseases $[9,46]$. A quasi-real-time, web-based platform, the European Centre for Disease Prevention and Control (ECDC) Vibrio Map Viewer (https:// e3geoportal.ecdc.europa.eu/SitePages/Vibrio\%20Map\% 20Viewer.aspx), was developed by the ECDC to monitor environmentally suitable marine areas for growth of pathogenic Vibrio ssp. [47••]. The ECDC Vibrio Map Viewer can detect environmental changes in marine environments around the world that are of public health importance. It uses a real-time model, based on daily updated remotely sensed SST and sea surface salinity (SSS) of coastal waters as inputs to map areas of high suitability for pathogenic Vibrio spp., demarcating coastal regions with suitable environmental conditions for infections in humans. The ECDC Vibrio Map Viewer provides a 5-day forecasting function that serves as an early warning system for Vibrio infections in the Baltic Sea. During a heat wave in 2014, suitable climatic (SST > $18 \mathrm{C}$ ) and environmental (SSS $>26$ practical salinity units) conditions were detected by the ECDC Vibrio Map Viewer in the Baltic Sea. Subsequently, an increase in vibriosis cases was detected in Sweden that were epidemiologically linked to the increase in SST [47••]. Similarly, in July 2018, the model showed a significant increase of the geographic extent of areas suitable for vibriosis in the Baltic Sea. The signal was linked to high temperature and drought conditions in several countries around the Baltic Sea. As vibriosis is not a communicable disease at the EU level, an alert was sent to the ECDC national focal points for food- and water-borne diseases and zoonoses in the countries around the Baltic Sea. At the end of the summer season, the number of vibriosis cases will be tabulated to assess if there was a temperaturerelated increase.

During the transmission season, ECDC uses the Vibrio Map Viewer forecasting function to monitor environmental conditions on a weekly basis and the findings are published in its Communicable Disease Threat Reports (CDTR) that is sent to public health decision makers in Europe. It provides options for action: public beach access can be temporarily restricted for public safety purposes; alerts can be disseminated when the environmental suitability of Vibrio infections is predicted; or warnings can be posted to notify health care providers and at-risk populations, such as the immunesuppressed.

\section{Conclusions}

Implementation of early warning systems using our knowledge of the relationships between infectious disease and environmental conditions can facilitate earlier detection and response to potential pathogen threats, and consequently reduce the burden of infectious diseases in human populations and associated costs. As changes in climate alter patterns of infectious disease and other health risks, early warning systems will be essential for mitigating the impacts on human populations. Building, employing, and maintaining these systems require collaboration between researchers and professionals in a diverse array of fields. Early warning systems for diseases like Vibrio cholera and related species, Rift Valley Fever, and dengue fever are in use, but they are in use in very specific regions, not fully utilized globally and much of the potential of these systems for other infectious diseases remains unexplored in both research and operational contexts, but the social and 
economic value of so doing is vast. The use of improved weather and climate forecasts and more advanced modeling techniques combined with increased collaborations between researchers and public health professionals can initialize a paradigm shift that moves away from lagged responses to disease threats and towards active, targeted strategies to predict and prevent epidemics before they start.

\section{Compliance with Ethical Standards}

Conflict of Interest The authors declare that they have no conflict of interest.

Human and Animal Rights and Informed Consent This article does not contain any studies with human or animal subjects performed by any of the authors.

\section{References}

Papers of particular interest, published recently, have been highlighted as:

- Of importance

-• Of major importance

1. Wu X, Lu Y, Zhou S, Chen L, Xu B. Impact of climate change on human infectious diseases: empirical evidence and human adaptation. Environ Int. 2016;86:14-23.

2. Liang L, Gong P. Climate change and human infectious diseases: a synthesis of research findings from global and spatio-temporal perspectives. Environ Int. 2017;103:99-108.

3. Servadio JL, Rosenthal SR, Carlson L, Bauer C. Climate patterns and mosquito-borne disease outbreaks in South and Southeast Asia. J Infect Public Health 2017:In Press.

4. Caminade C, Kovats S, Rocklöv J, Tompkins AM, Morse AP, Colon-Gonzalez FJ, et al. Impact of climate change on global malaria distribution. Proc Natl Acad Sci U S A. 2014;2014(111): 3286-91.

5. Hales S, de Wet N, Maindonald J, Woodward A. Potential effect of population and climate changes on global distribution of dengue fever: an empirical model. Lancet. 2002;360:830-4.

6. Semenza JC, Menne B. Climate change and infectious diseases in Europe. Lancet Infect Dis. 2009;9:365-75.

7. Hii YL, Zhu H, Ng N, Ng LC, Rocklöv J. Forecast of dengue incidence using temperature and rainfall. PLoS Negl Trop Dis. 2012;6: e1908.

8. Johansson MA, Reich NG, Hota A, Brownstein JS, Santillana M. Evaluating the performance of infectious disease forecasts: a comparison of climate-driven and seasonal dengue forecasts for Mexico. Sci Rep. 2016;6:33707.

9. Semenza JC, Sudre B, Oni T, Suk JE, Giesecke J. Linking environmental drivers to infectious diseases: the European environment and epidemiology network. PLoS Negl Trop Dis. 2013;7:e2323.

10. Butterworth MK, Morin CW, Comrie AC. An analysis of the potential impact of climate change on dengue transmission in the southeastern United States. Environ Health Perspect. 2017;125: 579-85 Demonstrates how shifts in climate conditions can impact the timing and longevity of vector and pathogen activity.
11. Struchiner CJ, Rocklöv J, Wilder-Smith A, Massad E. Increasing dengue incidence in Singapore over the past 40 years: population growth, climate and mobility. PLoS One. 2015;10:e0136286.

12. Ebi KL, Nealon J. Dengue in a changing climate. Environ Res. 2016;151:115-23.

13. Semenza JC, Lindgren E, Balkanyi L, Espinosa L, Almqvist MS, Penttinen $\mathrm{P}$, et al. Determinants and drivers of infectious disease threat events in Europe. Emerg Infect Dis. 2016;22:581-9.

14. Patil RR, Kumar CS, Bagvandas M. Biodiversity loss: public health risk of disease spread and epidemics. Ann Trop Med Public Health. 2017;10:1432-8.

15. Jones KE, Patel NG, Levy MA, Storeygard A, Balk D, Gittleman JL, et al. Global trends in emerging infectious diseases. Nature. 2008;451:990-3.

16. Constantin de Magny G, Colwell RR. Cholera and climate: a demonstrated relationship. Trans Am Clin Climatol Assoc. 2009;120: $119-28$.

17. Morin CW, Comrie AC, Ernst K. Climate and dengue transmission: evidence and implications. Environ Health Perspect. 2013;121: 1264-72.

18. Engelthaler DM, Mosley DG, Cheek JE, Levy CE, Komatsu KK, Ettestad P, et al. Climatic and environmental patterns associated with hantavirus pulmonary syndrome, four corners region, United States. Emerg Infect Dis. 1999;5:87-94.

19. Tamerius JD, Shaman J, Alonso WJ, Bloom-Feshbach K, Uejio $\mathrm{CK}$, Comrie AC, et al. Environmental predictors of seasonal influenza epidemics across temperate and tropical climates. PLoS Pathog. 2013;9:e1003194.

20. Tamerius JD, Comrie AC. Coccidioidomycosis incidence in Arizona predicted by seasonal precipitation. PLoS One. 2011;6: e21009.

21. Nakazawa T, Matsueda M. Relationship between meteorological variables/dust and the number of meningitis cases in Burkina Faso. Meteorol Appl. 2017;24:423-31.

22. Semenza JC. Prototype early warning systems for vector-borne diseases in Europe. Int J Environ Res Public Health. 2015;12:633351.

23. Lindgren E, Andersson Y, Suk JE, Sudre B, Semenza JC, Monitoring EU. Emerging infectious disease risk due to climate change. Science. 2012;336:418-9.

24. Descloux E, Mangeas $M$, Eugène Menkes $C$, Lengaigne $M$, Leroy A, Tehei T, et al. Climate-based models for understanding and forecasting dengue epidemics. PLoS Negl Trop Dis. 2012;6:e1470.

25. Morin CW, Monaghan AJ, Hayden MH, Barrera R, Ernst K. Meteorologically driven simulations of dengue epidemics in San Juan. PR PLoS Negl Trop Dis. 2015;9:e004002.

26. Sheridan S. A survey of public health perception and response to heat warnings across four North American cities: an evaluation of municipal effectiveness. Int J Biometeorol. 2007;52:3-15.

27. Anyamba A, Chretien J-P, Small J, Tucker CJ, Formenty PB, Richardson JH, et al. Prediction of a Rift Valley fever outbreak. Proc Natl Acad Sci U S A. 2009;106:955-9.

28. Sudre B, Rossi M, van Bortel W, Danis K, Baka K, Vakalis N, et al. Mapping environmental suitability of malaria transmission in Greece. Emerg Infect Dis. 2013;19:784-6.

29. Tseroni M, Baka A, Kapizioni C, Snounou G, Tsiodras S, Charvalakou M, et al. Prevention of malaria resurgence in Greece through the association of mass drug administration (MDA) to immigrants from malaria-endemic regions and standard control measures. PLoS Negl Trop Dis. 2015;9:e0004215.

30. Daszak P, Zambrana-Torrelio C, Bogich TL, Fernandez M, Epstein $\mathrm{JH}$, Murray KA, et al. Interdisciplinary approaches to understanding disease emergence: the past, present, and future drivers of Nipah virus emergence. Proc Natl Acad Sci U S A. 2013;110(Suppl 1): 3681-8. 
31. Semenza JC, Rocklov J, Penttinen P, Lindgren E. Observed and projected drivers of emerging infectious diseases in Europe. Ann N Y Acad Sci. 2016;1382:73-83.

32. Semenza JC, Sudre B, Miniota J, Rossi M, Hu W, Kossowsky D, et al. International dispersal of dengue through air travel: importation risk for Europe. PLoS Negl Trop Dis. 2014;8:e3278.

33. Hjelle B, Glass GE. Outbreak of hantavirus infection in the Four Corners Region of the United States in the wake of the 1997-1998 El Nino-Southern oscillation. J Infect Dis. 2000(181):1569-73.

34. Chowdhury G, Joshi S, Bhattacharya S, Sekar U, Birajdar B, Bhattacharyya A, et al. Extraintestinal infections caused by nontoxigenic vibrio cholerae non-o1/non-o139. Front Microbiol. 2016;7:144.

35. Heng SP, Letchumanan V, Deng CY, Ab Mutalib NS, Khan TM, Chuah LH, et al. Vibrio vulnificus: an environmental and clinical burden. Front Microbiol. 2017;8:997.

36. Letchumanan V, Chan KG, Lee LH. Vibrio parahaemolyticus: a review on the pathogenesis, prevalence, and advance molecular identification techniques. Front Microbiol. 2014;5:705.

37. Baker-Austin C, Trinanes J, Taylor N, Hartnell R, Siitonen A, Martinez-Urtaza J. Emerging vibrio risk at high latitudes in response to ocean warming. Nat Clim Chang. 2012;3:73-7.

38. Banakar V, Constantin de Magny G, Jacobs J, Murtugudde R, Hug A, Wood RJ, et al. Temperal and spatial variability in the distribution of Vibrio vulnificus in the Chesapeake Bay: a hindcast study. Ecohealth. 2011;8:456-67.

39. Baker-Austin C, Trinanes J, Gonzalez-Escalona N, MartinezUrtaza J. Non-cholera Vibrios: the microbial barometer of climate change. Trends Microbiol. 2017;25:76-84.

40. Trtanj J, Jantarasami L, Brunkard J, Collier T, Jacobs J, Lipp E, et al. Climate impacts on water-related illness. Chapter 6 in the impacts of climate change on human health in the United States: a scientific assessment. Washington, DC: US Global Change Research Program; 2016. p. 157-88.

41. Andersson Y, Ekdahl K. Wound infections due to vibrio cholerae in Sweden after swimming in the Baltic Sea, summer 2006. Euro Surveill. 2006;11:E060803.060802.

42. Baker-Austin C, Trinanes JA, Salmenlinna S, Lofdahl M, Siitonen A, Nick GH, et al. Heat wave-associated vibriosis, Sweden and Finland, 2014. Emerg Infec Dis. 2016;22:1216-20.
43. Dalsgaard A, Frimodt-Moller N, Bruun B, Hoi L, Larsen JL. Clinical manifestations and molecular epidemiology of vibrio vulnificus infections in Denmark. Eur J Clin Microbiol Infec Dis. 1996;15:227-32.

44. Lukinmaa S, Mattila K, Lehtinen V, Hakkinen M, Koskela M, Siitonen A. Territorial waters of the Baltic Sea as a source of infections caused by vibrio cholerae non-o1, non-o139: report of 3 hospitalized cases. Diagn Microbiol Infec Dis. 2006;54:1-6.

45. Ruppert J, Panzig B, Guertler L, Hinz P, Schwesinger G, Felix SB, et al. Two cases of severe sepsis due to vibrio vulnificus wound infection acquired in the Baltic Sea. Eur J Clin Microbiol Infec Dis. 2004;23:912-5.

46. Nichols GL, Andersson Y, Lindgren E, Devaux I, Semenza JC. European monitoring systems and data for assessing environmental and climate impacts on human infectious diseases. Int J Environ Res Public Health. 2014;11:3894-936.

47.• Semenza JC, Trinanes J, Lohr W, Sudre B, Löfdahl M, Martinez Urtaza J, et al. Environmental suitability of Vibrio infections in a warming climate: an early warning system. Environ Health Perspect. 2017;125:107004 Provides an example of an early warning system that was able detect high risk conditions of a pathogen in advance of case observations.

48. Semenza JC, Tran A, Espinosa L, Sudre B, Domanovic D, Paz S. Climate change projections of West Nile virus infections in Europe: implications for blood safety practices. Environ Health. 2016;15: S28.

49. Davis JK, Vincent G, Hildreth MB, Kightlinger L, Carlson C, Wimberly MC. Integrating environmental monitoring and mosquito surveillance to predict vector-borne disease: prospective forecasts of a West Nile virus outbreak. PLoS Curr Outbreaks. 2017;1.

50. Shaman J, Kandula S, Yang W, Karspeck A. The use of ambient humidity conditions to improve influenza forecast. PLoS Comput Biol. 2017;13:e1005844.

51. Pasetto D, Finger F, Camacho A, Grandesso F, Cohuet S, Lemaitre $\mathrm{JC}$, et al. Near real-time forecasting for cholera decision making in Haiti after Hurricane Matthew. PLoS Comput Biol. 2018;14: e1006127.

52. Merkord CL, Liu Y, Mihretie A, Gebrehiwot T, Awoke W, Bayabil $\mathrm{E}$, et al. Integrating malaria surveillance with climate data for outbreak detection and forecasting: the EPIDEMIA system. Malar J. 2017;16:89. 